\title{
The new Italian code of medical ethics
}

\author{
Vittorio Fineschi, Emanuela Turillazzi and Cecilia Cateni University of Siena, Italy
}

\begin{abstract}
In Fune 1995, the Italian code of medical ethics was revised in order that its principles should reflect the everchanging relationship between the medical profession and society and between physicians and patients.

The updated code is also a response to new ethical problems created by scientific progress; the discussion of such problems often shows up a need for better understanding on the part of the medical profession itself.

Medical deontology is defined as the discipline for the study of norms of conduct for the health care professions, including moral and legal norms as well as those pertaining more strictly to professional performance. The aim of deontology is therefore, the in-depth investigation and revision of the code of medical ethics. It is in the light of this conceptual definition that one should interpret a review of the different codes which have attempted, throughout the various periods of Italy's recent history, to adapt ethical norms to particular social and health care climates.
\end{abstract}

\section{Riassunto}

Nel giugno 1995 è stato promulgato il nuovo codice di deontologia medica in opportuna coerenza con il divenire del rapporto tra medicina e società e tra medico e paziente ed in armonia con la riflessione bioetica sui problemi posti dal progresso scientifico e dalla evoluzione sociale alla professione medica.

Il codice di deontologia medica si propone come protocollo comportamentale per tutti i medici e, seppure non rivesta nel nostro ordinamento il valore della legge, tuttavia costituisce un essenziale riferimento in sede di interpretazione e di applicazione del diritto.

Particolarmente definiti risultano $i$ temi del consenso informato, della fecondazione artificiale ed $i$ principi della tutela della salute e della vita, considerati nel più ampio rispetto della dignità e della libertà della persona. $E$ ' ancora troppo presto per considerare definitiva la

\section{Key words}

Medical ethics; Italian code; deontology.

\section{Parole chiave}

Etica medica; codice italiano di deontologia medica. generale adesione che il codice sembra avere ricevuto da parte dei medici italiani. Questo sia perché i medici non hanno ancora avuto modo di valutare le nuove regole individualmente o all'interno delle società scientifiche, sia perché non esiste un precipuo interesse in merito a tali argomenti. Solo una minoranza dei medici italiani si è resa effettivamente conto che la medicina è di fronte sempre e quotidianamente a laceranti dilemmi ed è chiamata a ripensare il senso della propria pratica.

\section{Introduction}

Only five years after what seemed to be a definitive rendition of the Italian code of medical ethics (1989), a need arose in Italy to revise the conceptual framework of the norms concerning the duties of physicians. Guided by innovative principles emerging from current considerations of bioethics, this revision culminated, in June 1995, in the formulation of a new code, ${ }^{1}$ adapted, as any ethical guidelines should be, to reflect the constantly changing relationship between the medical profession and society, and between physicians and patients, the latter relationship being a frequent source of conflict between two autonomous parties who share the intention to protect fundamental human rights in the administration of care but whose immediate health care goals do not necessarily coincide. The updated code is also a response to new ethical problems created by scientific progress: the discussion of these new ethical problems often reveals a need in the medical profession itself for better understanding and definitions. Of course, the code of medical ethics does not aim to impose the physician's perspective on society, but to contribute to the clarification of extremely delicate issues around which there is vigorous ethical debate and rare consensus. Moreover, the ethical debate is fuelled by a strong awareness of the difficulties surrounding the formation of a normative path in such arduous terrain as that of assisted reproduction, embryo management, euthanasia, living wills, etc, and the discussion is enriched by the profoundly different perspectives of the pluralistic culture which forms its background.

In March 1990, a national committee for the study of bioethics (Comitato Nazionale per la Bioetica, 
or CNB) was established in Italy. ${ }^{2}$ It serves as a consulting body to the council of ministers, whose primary task is to suggest policy directions and make recommendations for the enactment of laws pertaining to the fundamental ethical and legal problems that continuously arise in the practice of medicine and in scientific research with human subjects. The proposals of this committee have significantly influenced the drafting of the new ethical code, especially in those areas where ethical conflict is most intense.

The rich bioethical background has contributed greatly to the formulation of a code of professional conduct which is "innovative and as free as possible from the strict confines of the law, which proposes and gives theoretical support to the duties and risks of the profession, and acts as a guideline for social and legal regulation not so much in terms of the merit or legitimacy of each scientific enterprise and medical performance, but in terms of their ethical quality. The code takes into account the laws of the state, the professional norms, and the advice of international bodies, gives substance and continuity to ethical committees, and expresses itself in the biomedical environment, with the clarity and conscientiousness typical of this field of legal medicine". ${ }^{3}$ The delicate interaction between the academic study of bioethics and professional codes of ethics has made it necessary to redefine the confines of each and, in fact, a document which addresses this subject was produced in Erice (Italy) during bioethics day at the 53rd course on "New Trends in Forensic Haematology and Genetics: Bioethical Problems."4

Medical deontology is therein defined as a discipline for the study of the norms of conduct for health care professionals. This includes moral and legal norms as well as those pertaining more strictly to professional performance. It can be ascertained that from the times of the Corpus Hippocraticum "deontology is a moral philosophy that aspires to become a legal right". 5 Each deontological norm, together with each code of professional self-regulation should distinguish itself: by its defence of the profession; by its commitment to new values; by its support of tradition as well as its support for the evolution of customs, and by strengthening certain behavioural limitations and overcoming others. ${ }^{6}$

Our hope is that the final options formulated by the deontological medical code will root themselves in tomorrow's society. It is, without doubt, commendable that in a society characterised as "the culture of disbelief", ${ }^{7}$ physicians have continued to act as navigators "who rarely rely upon celestial navigation. Usually they have nautical charts made by those that preceded them to give them a general sense of their position and their geographic situation". 8

On July 19, 1910, a law was passed in Italy which not only sanctioned the establishment of professional associations of health care providers but also recognised the important disciplinary role of such organisations in repressing abuses and negligence committed by members in their professional pract. tices, with the exception, of course, of those cases already recognised and punishable according to pre: existing laws and regulations. This implicit recognif? tion of an official role helped to sow the seeds legally-supported professional autonomy and sel sufficiency in matters of regulation and disciplinee The provisions consequently formulated (191 $1913,1928,1929,1935$ ) in order to make that fir law effective, instead of contributing to the establish ment of a vague normative code, remained focused on delineating the procedural aspects of the disciplis nary actions and sanctions. Although it has, in effecos? become primarily an operational tool, a way dealing with disciplinary matters, there is no explicio mention of an ethical code even in the most recent regulations (1950), which simply elaborate furthe्g on the disciplinary aspect.

The first codes of ethical conduct appeareg between 1918 and 1924, springing from the locat initiatives of provincial medical associations, espe cially the one in Turin. The first official and detaile document was published by that highly respected organisation in 1948. Five years later, an ad $h \overrightarrow{Q 6}$ national commission of physicians was established for the study of the document and in 1954, following the positive evaluation of this work by Association for Legal Medicine of Rome, the cont mission issued the Codice Frugoni (Frugoni Coded, so called after the illustrious clinician who was i most fervent promoter.

The consequent editions of 1978 and 1989 gaine organic unity and benefited extensively from the contribution of the specialists in legal medicine whe were recruited for the various commissions which the Federation of Medical Associations established to oversee the revisions. The codes of ' 78 and ' 88 were increasingly sensitive to the evolving heali care system and specific social climate of the country, while at the same time remaining focused on the factors which were decisive in extending and modifying many of the traditional duties and privi leges of the medical profession. Such factors include extraordinary achievements in medicine, pharmacot ogy and biotechnology; the spread of those social behaviours that influence the health of individuals and populations; decisive legislative regulations of matters such as the definition of health and of medical treatment (optional v mandatory), abortios, and treatment of drug addiction, all of which have increased and modified, to some extent, the trade tional duty and consolidated authority of the medical practitioner.

The penultimate 1989 edition of the colf addressed a complex series of ethical issues regar\%ing the professional relationship not only witi patients but also with third parties, both private and public, and ventured into vast ethical topics 
untouched in previous editions, including that of sports medicine, prevention of, and intervention in, cases of doping, and the doctrine of informed consent. The various editions that followed have been progressively adapted to the changing times, culminating finally in the 1995 draft. The 1989 code placed particular emphasis on defining the protagonists of the therapeutic relationship. It gave ample consideration to the patient as a whole person whose dignity, liberty, equality and right to life and to health care are to be respected, and it considered the role of physicians in regard to the individual and society, fully appraising and providing the means for the protection of their profession. The 1989 code was altogether more comprehensive than its predecessors but, because it deals with particular areas of health care activity, for instance social matters, artificial reproduction, experimentation and drug use, it was liable to modification in a short period of time. In fact, contrary to the previous ad hoc commissions, the 1989 commission was given a permanent mandate to review the code periodically, ${ }^{9}$ because of the changing needs of the profession. Deontology is becoming a response to the need for constant monitoring, sensitive to both social and legal demands, of scientific progress. Thus, what emerges is acknowledgement of the absolute importance of a medical deontology which takes into consideration the essential behavioural guidelines that the physician must be inspired by, and adhere to, in a fixed juridical social order that cannot disregard the relationship between medicine and society or between physician, health care structure and patient.

In effect, medical deontology studies the relationship between medical practice in both its scientific and professional aspects, as well as its relationship to general and juridical social changes and laws. It is, in fact, a doctrine that associates the physician's responsibility and authority with the individual's and society's expectations of the medical profession and finally, with each person's rights. The deontological code must therefore be open to constant revision if it is to remain an effective and useful behavioural model. In our country, especially at present, progress in the biomedical sciences and pharmacology, together with social changes which greatly influence individual and collective health, has amplified and modified many of the physician's traditional duties. The Italian Medical Association's code is therefore not only an elaboration of the deontological code, but also an evaluation and rejection of anything that appears unbecoming to professional standards. Penal regulation is inspired by a principle of appropriateness whereby every action or prohibited omission to act is defined in each of its aspects. According to this regulation a penalty is inevitably induced according to the principle of "nullum crimen, nulla poena sine lege" ( no crime, no punishment without law). The deontological regulation, however, does not define the prohibited behaviour in each of its aspects, but rather, limits itself to recognising generic hypotheses, leaving the application, in each specific case, to the medical association. In compiling and enforcing its own code, the Italian Medical Association expresses, in fact, an exemplary model of medicine. The code naturally subscribes to the state laws and norms in democratic regimes, but there will be certain areas where approaches differ from, or are openly contradictory of, state laws. For example, there are no laws in Italy which regulate assisted reproduction but the Italian code of medical ethics contains explicit restraints. In a democratic country the state laws will naturally prevail, but these could be revised or applied with greater pertinence, in order better to recognise the needs of the medical profession. Many, in Italy, aspire to a more effective code of medical deontology which not only gives examples and advice, but which also assumes the role of an actual law as happens in France where "La Code de Deontologie Medicale" is a legislative act, issued by the prime minister and published in the fournal Officiel de la Republique Francaise. ${ }^{10}$

\section{The principles of the new Italian code of medical ethics}

A brief analysis of the most significant points of the new code should bring one's attention to the profound change that underlines the relationship between physician and patient. In the course of a lengthy evolution that has influenced the drafting of previous deontological codes, a confrontation of the two subjects involved in the medical act, physician and patient, has passed from a situation of preeminence on the part of the former, to one of absolute equality, in which each takes on his or her respective spheres of competence, autonomy and choice. In other words, from a paternalistic attitude in which the physician, for the good of the patient, felt authorised and justified to set aside the personal requests of the patient and even to violate his wishes, a therapeutic alliance has evolved, ${ }^{6}$ in which the two partners together try to decide on the clinical choices that best promote the patient's wellbeing. The new code demonstrates, at various points, this added perspective in the therapeutic relationship. Article three, in fact, introduces the physician's obligation not only to "respect the dignity of the human being" (code 1989), but also the patient's freedom of choice". Article four reaffirms the physician's freedom of choice and scientific freedom to practise as a fundamental premise of the medical profession, and also peremptorily states, the physician's obligation to " respect the rights of the individual".

It proposes that the conduct of the physician should find inspiration in the equilibrium and interplay between science and conscience, a middle ground conducive to responsible medical performance and to the fulfilment of the patient's interests.

Article 17 states: "A trait of the physician's relationship with his patient must be the respect for the 
fundamental rights of the person", and proposes an exact delineation of the position of the medical professional, which faithfully adheres to the fundamental principles of our constitution (articles two and three). The preceding codes did not contain an analogous precept, if we exclude the provision of article 25 in which the physician is obliged to abstain from influencing the moral, political and religious opinions of the patient. The present position requires the physician actively to protect and respect the fundamental rights of the patient, clearly outlining all the possibilities of treatment. This increased perception of the patient's freedom does not, however, stop the code confirming the physician's fundamental obligation to respect and defend the patient's life, physical and mental health and to relieve his suffering (article three). In this way, the deontological regulation intends to underline the existing link between the medical profession and the defence of humanity's rights and dignity. ${ }^{11}$

The code is particularly specific in its treatment of medical freedom of choice regarding the issue of the physician's right to moral objection. Indeed, with the advent of assisted reproduction, experimentation with embryos, transplantation and genetic manipulation, it appears that the therapeutic options offered to the patient are increasingly subject to the personal convictions of the physician. The code is firm in reasserting the physician's liberty to refuse to undertake a medical course of action to which his conscience or his personal clinical judgment is opposed, except in those instances in which the physician's refusal threatens the safety of the patient. The most innovative aspect of the code extends the physician's obligation to intervene not only in cases of life and death, but also when his refusal could cause grave and immediate harm to the patient. Hence, the margin of discretion afforded the clinician is further defined by his duty to protect not only the life, but also the wellbeing of the patient.

The physician's right to freedom of choice is therefore limited by a conflict with other rights (the patient's) guaranteed by the constitution (for example, the right to public welfare), and therefore the former's freedom of choice can only be legitimately practised when defined by a legislative regulation. The search for laws capable of resolving this conflict appears futile in an era in which the evolution of medical science gives rise, with increasing frequency, to situations in which the therapeutic option is notably influenced by the physician's personal convictions (artificial reproduction, embryonic experimentation, transplants, euthanasia, genetic manipulation. ...). In fact, our legislative regulation admits only two possible situations where conscientious objection is acceptable on the part of health care practitioners: one concerning voluntary abortion (law 25 May 1978, no194), and the other concerning experimentation on animals (law 12 October 1993, no 413).
In this legislative setting, the deontological lavi that underlines the physician's right to refuse tor intervene, except in emergency cases, assumes par ticular relevance, even though it does not supply? concrete solutions for all of those cases where the physician's convictions clash with the patient's will?

Another limit to the physician's autonomy is the patient himself: here, in the articles concerninge informed consent, the code adopts a strong position $\overrightarrow{\mathbb{D}}_{\vec{D}}$ In order for any medical activity to take place the wilP of the patient must be properly established and legit tos imately expressed.

The traditional approach, based on an ethic of beneficence, in which the paternalistic physiciarf more or less unabashedly filters or manipulates: information in order to convince, if not force, the patient to adhere to a therapeutic course of action presumed to be in the patient's best interest, has finally given way to a liberal ethic which encourages the patient's self-determination and gives new legitis macy to the medical act by also legitimising the patient's freedom of choice. The National Bioethics Committee (CNB), while remarking on the insepa rability of the concepts of consent and information also noted that each of these has distinct ethicaf origins which precede their bioethical or judicial for $\vec{\emptyset}$ mulation. The code, in fact, addresses these tgov components of informed consent separately.

In its detailed description of the methodology providing information within the therapeutic re tionship, the code echoes the recommendation made in a recent document by the $\mathrm{CNB}$ on informed consent. The information provided must be objec $\overrightarrow{\vec{T}}$ tive and complete, and must include an explanation of the diagnosis, therapeutic options, risks and benefits of treatments or refusals of treatment, an prognoses. Furthermore, the information must be presented in a manner which is compatible with the्ల individual patient's educational level, comprehen-sion skills, and psychological and emotional status? and must be, therefore, conducive to a full ano accurate understanding.

The current Italian code of medical ethics adopto a doctrine of consent which is nearer to those preva lent in most modern codes, whereby a physiciar? cannot intervene without the expressed permission of the patient. This injunction to respect the decios sional autonomy of the patient remains valid even irf cases which threaten the very life of the patient. The obligation to obtain consent prior to treatment is waived only when: 1) the treatment is required bob law; and 2) a decision is urgently needed and it iह impossible to determine the patient's wishes (ie the patient is incompetent). In the second instance, theo judgment of the physician becomes paramount: the code offers little guidance here and the physician supported only by his personal ethical sensitivity remains solely responsible for the decision Situations of patient incompetence occur frequently at the end of life. ${ }^{12}$ Yet, while the code reiterates the 
importance of an evaluation of medical utility $\mathrm{v}$ the interests of the patient, only minor changes have been made to the sections on care of the dying and life-sustaining treatments. It is interesting to note that, unlike many codes of ethics, the Italian code does not, in cases of patient incompetence, defer to the consent or participation in decision-making of third parties (substitute decision-makers or proxies). The code eliminates any doubt around the presumed, though unfounded, role of relatives in decision-making, an altogether coherent position since the law does not afford the next of kin any such right or responsibility. Also, no recommendations are mentioned regarding living wills, even though the CNB and many other authoritative bioethical organisations in Italy have debated the topic, often encountering bitter conflict in the literature on this topic between Catholic bioethicists and those of nonCatholic traditions. The Italian legal system presents many complications regarding the application of advanced directives, either for, or against treatment. An eventual withdrawal of medical assistance, indicated in a living will, that causes a patient's death could be considered as a homicide.

Article five of the civil code forbids any use of one's own body which can cause permanent damage. The patient's autonomy, in this case, is not protected. Nor is it in article 32 of the constitution: patients can decide to accept or to refuse a treatment only when they are conscious and able to express their will. In this debate, one italian philosopher prefers to take a middle course that considers the living will an orientative rather than an injunctive document which clarifies the wishes and emotions of patients before they lose consciousness. ${ }^{13}$

Some changes were made to the present code on the topic of confidentiality. In the case of extremely negative prognoses, the previous code permitted the physician to hide the truth from the patient and reveal it instead to the next of kin. Compelled by a previous statement of the CNB, which confirmed the exclusive right of the competent patient to the truth, the new code makes a striking advance in this respect by prohibiting the option of non-disclosure of prognoses to the patient and that of disclosure to third parties. There are two exceptions to this rule of confidentiality. The first, of course, is when disclosure is specifically authorised by the patient. The second occurs when there is potential for harm to a third party. Since the 1990 law on HIV has specifically prohibited the revelation to third parties of a patient's HIV infection, the debate on this issue has flourished. The code treads on some delicate ground by suggesting that there is a duty to inform partners or family of the patient's condition in these cases.

However, the code's true innovation is represented by the article dedicated to the problems surrounding assisted reproduction: faced with a persistent lack of legislation, it supplies precise and detailed instructions for doctors.
In the hope of inspiring future legislation, the CNB issued a document in June 1994 in which general recommendations and ethical guidelines were delineated for some of the focal points of the debate, such as surrogate motherhood, admission criteria for these services, sperm donation and embryo management. With its decision to adopt neutral terminology, the code reflects the CNB's position in its treatment of these themes and provides a general orientation for physicians. The term "artificial" is purposely avoided in favour of "assisted" procreation, and the series of techniques and procedures is described simply as "a new method of reproduction". This preliminary choice of value-free language in which positive and negative connotations are abolished is not to be underestimated in its contribution to a fair assessment of the ethical legitimacy of such procedures. ${ }^{14}$

Whether or not the new reproductive techniques are defined as medical treatment could also greatly influence the bioethical debate. The code clearly states that the aim of reproductive technologies is "to circumvent infertility for the legitimate purpose of procreation," and thus justifies these options on the grounds of their therapeutic value. On the specific uses of such techniques, the code (perhaps due to the persistent reluctance among legislators to regulate these matters) is somewhat categorical. It strictly admonishes against participation in any form of surrogate motherhood. This position reflects that of the CNB and is based on the principle that commercialisation of the human body is wrong; it further reflects the concern that displacement of parenthood from the traditional nucleus represents a grave threat to the wellbeing, especially psychological, of the parties involved. The potential newborn is seen to be particularly at risk as a result of the "fragmentation" of the maternal figure. The welfare of the newborn is at the root of the code's rigid stance on the criteria for admission to programmes for assistance in reproduction. The best conditions into which a child can be born are presumed to be those provided by an adult, heterosexual couple, preferably married or in a long-standing, loving relationship. It is also suggested that the couple be of an age when the potential for fertility is high. In this way, the Italian code prohibits physicians from providing assistance in reproduction to all but stable, heterosexual couples, therefore excluding women who are single or widowed, or post-menopausal.

Finally, the code underlines the need for systematic regulation of programmes for assistance in reproduction, and provides a series of specific criteria which clinics offering such services should meetl. If respected, this last recommendation will bring the Italian situation closer to that of many modern nations where the law not only regulates the provision of reproductive techniques but also provides for the protection of the health of those who avail themselves of such services. With the proliferation in Italy 
of ad hoc private centres for assisted reproduction, the lack of quality control, in terms of medical professionalism and of procedural and equipment standards, has become an urgent concern.

The need for legislative regulation emerges with absolute priority in the provocative debate on themes related to assisted reproduction. Unanimous criticism is directed toward so-called "abstentionists". Both the abstensionism supported by the Catholic Church, which judges any form of assisted procreation as illicit, and the abstensionism which views lack of legislation as a healthy liberalisation of bio-techniques, have been the cause of numerous failures on the part of the italian legislation to arrive at the promulgation of a law. In this context the deontological code, pronouncing, as it does, explicit restraints regarding assisted reproduction, anticipates any legislation. The risk, however, of an anticipatory code is that of subsequent rejection by legislators who could opt either for more liberal solutions, inspired by the Spanish or English law, or more rigid solutions, like those imposed by German law.

In substance, the medical establishment has prudently expressed, through the code, not only a technical but also an ethical judgment, which is concerned with defending society's essential values, such as the stability of the family and the wellbeing of the newborn. A rigidly prohibitional stance would have restrained any form of assisted reproduction, while an overly permissive stance would have accepted any novelty.

The physicians' decree is noteworthy in the light of the absence of legislation, ${ }^{6}$ even though numerous voices have been raised in Italy against the medical association for 1 . promulgating explicit prohibitions regarding matters which properly belong under the jurisdiction of parliament and 2. for making an ethical evaluation which the medical profession cannot legitimately make.

\section{Conclusions}

It is still too early to consider as definitive, the general consensus that the code seems to have received on the part of Italian physicians. This is due to the fact that the physicians have not yet been able carefully to evaluate the new laws, either individually or as a scientific body, and also because among doctors there still persists a notable lack of interest and superficiality regarding these topics. Without a doubt the code can be credited with validating and ensuring the new democratic quality of the physician-patient relationship - the non-neutrality that clearly favours the respect for and protection of the patient's physical and mental health and life. And it is true to say it has an innovative character, in that it is concerned with important topics, for example assisted reproduction, in the absence of any state legislation on these matters.
Danger exists in the ambiguity entailed in cons bining democracy and non-neutrality. In fact, the freedom and dignity of the human being express stated as a constitutive right by the new deontologe cal code, conceals a cultural clash between liberas and Catholics, which must emerge in time and cause behavioural uncertainties among health care practs tioners, especially concerning those questions le unanswered by a legislation that refuses to mak choices in an area where not only unity but evef mere medical consent is difficult to find.

Vittorio Fineschi, MD, PhD in Deontology and Medicat Ethics, is a Consultant in Forensic Medicine ars Insurance, a University Teacher in the Department Forensic Medicine of the University of Siena, and $\overleftrightarrow{a}$ Collaborator of the Department of Bioethics of the University of Toronto. Emanuela Turillazzi, MD, Ph in Deontology and Medical Ethics, and Cecilia Catencs

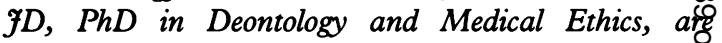
Assistants in the Department of Forensic Sciences University of Siena, Italy.

\section{References}

1 Fineschi $\mathrm{V}$, ed. Il codice di deontologia medica. Milan $\vec{\omega}$ Giuffrè, 1996.

2 Comitato Nazionale di Bioetica. Bioetica e formazing nel sistema sanitario. comitati etici. Formazione e constn all'atto medico. Parere del CNB sulle tecniche di profrs azione assistita. Roma: Istituto Poligrafico e Zecca dêlচ Stato, 1996.

3 Barni M. La medicina legale e le etiche esterr alla legge. Rivista Italiana di Medicina Legale 1991; 13. 375-80.

4 Ettore Maiorana Centre for Scientific Culture. Nequ trends in forensic haematology and genetics. Bioethicg problems. Erice, Italy: Ettore Maiorana Centre fo⿺ Scientific Culture, 1991.

5 Debray J. Le malade est son médecin. Paris: Flammariof, 1965.

6 Cattorini P. Il nuovo codice di deontologia medica:co siderazioni etiche. Rivista Italiana di Medicina Legahe 1996; 1: 55-70.

7 Carter SL. The culture of disbelief. How american law ard politics trivialize religious devotion. New York. In; Busnelli FD. Il codice di deontologia medica. Mila Guiffre, 1996.

8 Jonsen AR. Clinical ethics and the four principles. F Gillon R, Lloyd A, eds. Principles of health care ethiqs Chichester: John Wiley, 1994.

9 Lega C. Manuale di bioetica e deontologia medic $\$$ ? Milano: Giuffrè, 1991.

10 Décret no 95-1000 du 6 septembre 1995 portant da code de déontologie médicale.

11 Busnelli FD. Opzioni e principi per una disciplina nof mativa delle biotecnologie avanzate. Rivista Critica ti Diritto Privato 1991; 2: 283-304.

12 Hope T. Advance directives. Fournal of Medical Ethios 1996; 22: 67-8.

13 Bondolfi A. Il tema del living will nel dibattito sum buona morte. KOS 1992; 76: 18-21.

14 Mori M. La fecondazione artificiale. Bari: Laterza Editore, 1995. 